\title{
In pursuit of Layia DC. (Madieae): Unexpected insights from field work in the land of little rain
}

\author{
Isaac Lichter-Mark' (i) \& Bruce Baldwin' (i) \\ 'Jepson Herbarium \& Dept. of Integrative Biology, I 00 I Valley Life Sciences BIdg. \#2465, University of California, Berkeley, CA 94720-2465, \\ bbaldwin@berkeley.edu, ilichtermarck@berkeley.edu
}

DOI: http://dx.doi.org/| 0.53875/capitulum.0 0 . I.09

Keywords: budding speciation, drought, fire, Mojave Desert.

When telling colleagues and friends you'll be out in the field collecting wildflowers for a couple weeks, they imagine you leisurely walking in the fields, taking in the sights and sounds, and occasionally stopping to pick sunflowers and daisies. Sometimes fieldwork does actually work out this way, but usually the leisurely moments are far outnumbered by the times when you feel uncomfortable, tired, or caught off guard by unexpected obstacles. Some of the most amazing field work experiences happen when everything completely falls apart, though, even in catastrophic, almost comedic ways, and yet still leads to unanticipated, mind-blowing scientific discoveries. This was the case with our recent field work (Figure I) as part of research into the whole genome phylogeography of Layia glandulosa Hook. \& Arn., a state-funded project that was approved in the spring of 2020, just before the world fell apart.

Layia glandulosa (Figure 2) is the most geographically widespread self-incompatible annual in the tarweed and silversword tribe (Madieae Jeps.). It has been the subject of evolutionary studies of speciation in the past for its peripatric progenitor-derivative species relationship with the narrowly endemic serpentinite specialist species Layia discoidea D.D. Keck. It turns out that $L$. discoidea is nested within $L$. glandulosa in phylogenetic analyses, suggesting that despite being so morphologically distinct that it was previously placed in a separate tribe, $L$. discoidea is the recent derivative of a presumably extreme natural selection event. We sought support in 2019 to investigate in greater detail the evolutionary history of this fascinating species complex and to use whole genome data to understand the dynamics of budding speciation. As part of our proposal, we promised to collect I 00 spatially separate populations of L. glandulosa and L. discoidea across their ranges in California. Layia glandulosa is a common and sometimes abundant part of the ephemeral wildflower blooms that carpet cismontane and desert habitats in California after rain, so as long as there was some precipitation, we did not feel that meeting our goal of 100 populations was an unrealistic promise.

Covid- 19 reached California soon after the beginning of 2020 and community spread led to the shutdown of normal life just as the spring wildflowers were beginning to bloom. Of course we canceled our plans to collect L. glandulosa in spring 2020 rather than increase the risk of transmission of coronavirus, and were forced to watch the Layia DC. blooms from afar through posts on iNaturalist. We told ourselves we would have another chance in spring 202I to do our field work, without risk of putting more 


\section{May your trails be winding, crooked, lonesome, dangerous, leading to the most amazing view.}

Edward Abbey
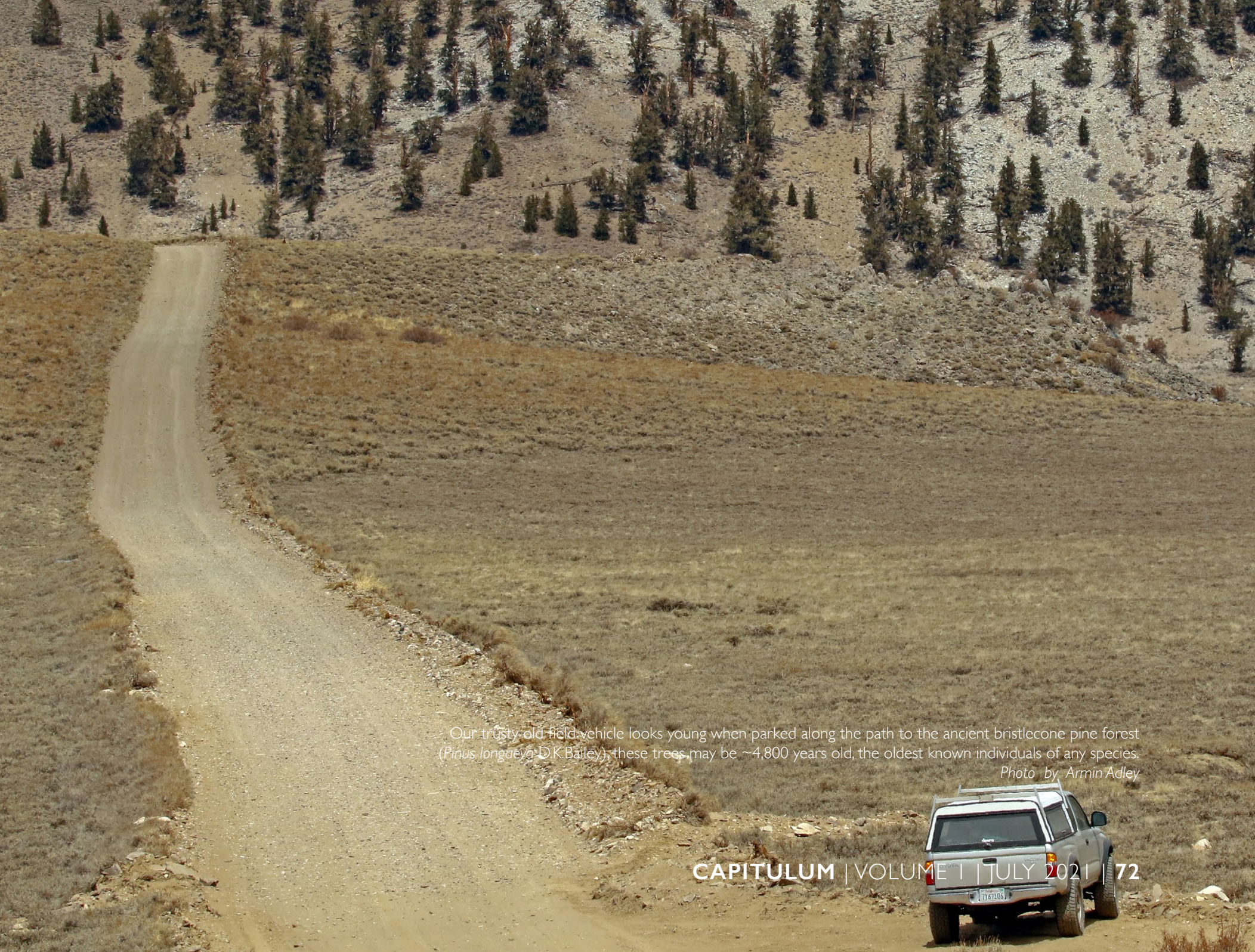


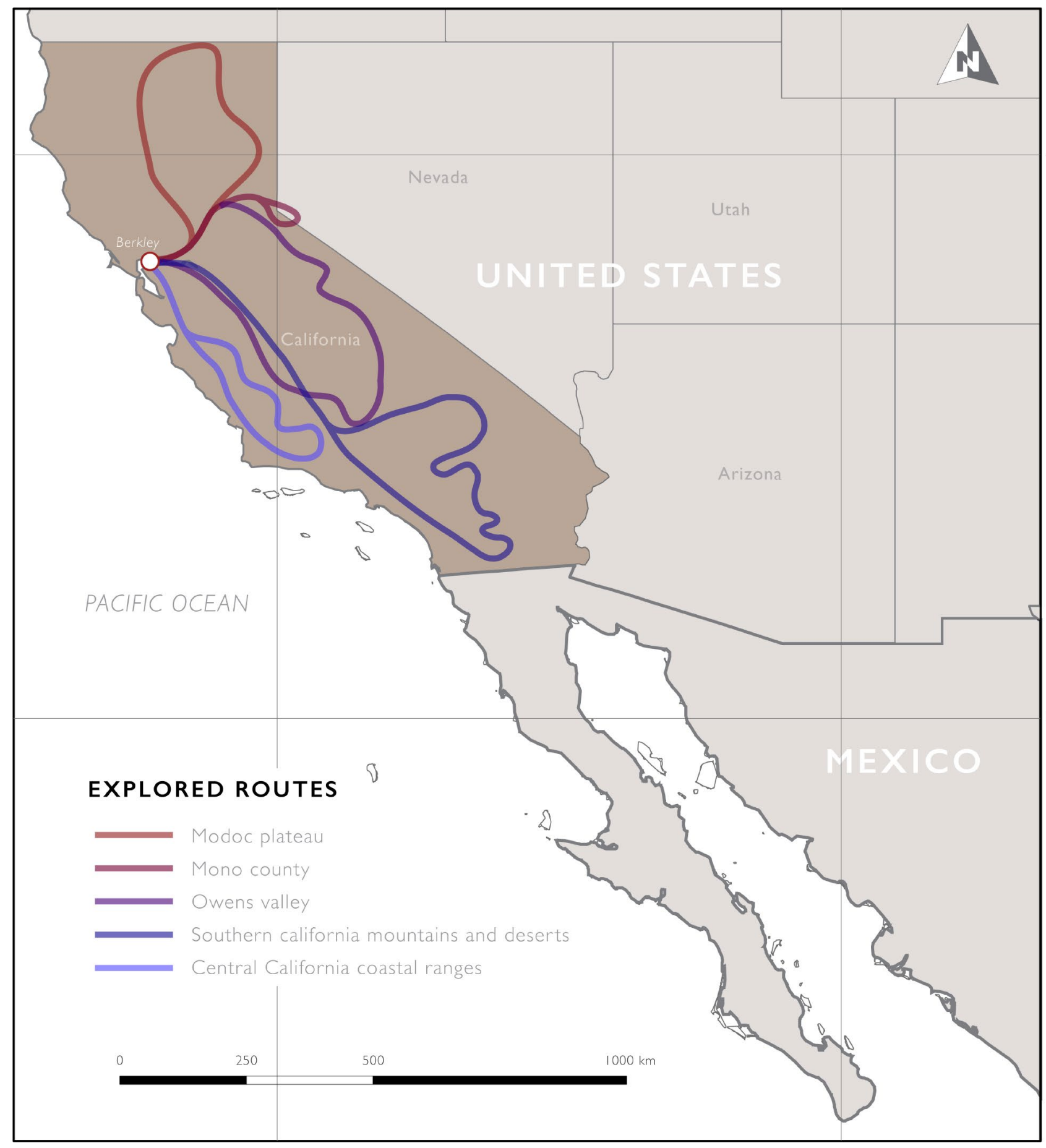

Figure I. Approximate routes followed in search of Layia DC.

pressure on an already stressed healthcare system. Nature had other plans, though. Climate change hit California hard in the summer of 2020, with historic widespread heatwaves that ended up producing the highest temperatures on record for the state, I 32 degrees in Death Valley National Park. The intense heat, coming during the driest part of the year in the western U.S. produced a rash of never-before seen dry lightning that ignited over $\sim 6000$ fires in one week. While many evacuated their homes or took shelter from the thick blankets of wildfire smoke, lots of national forests in California closed to the 


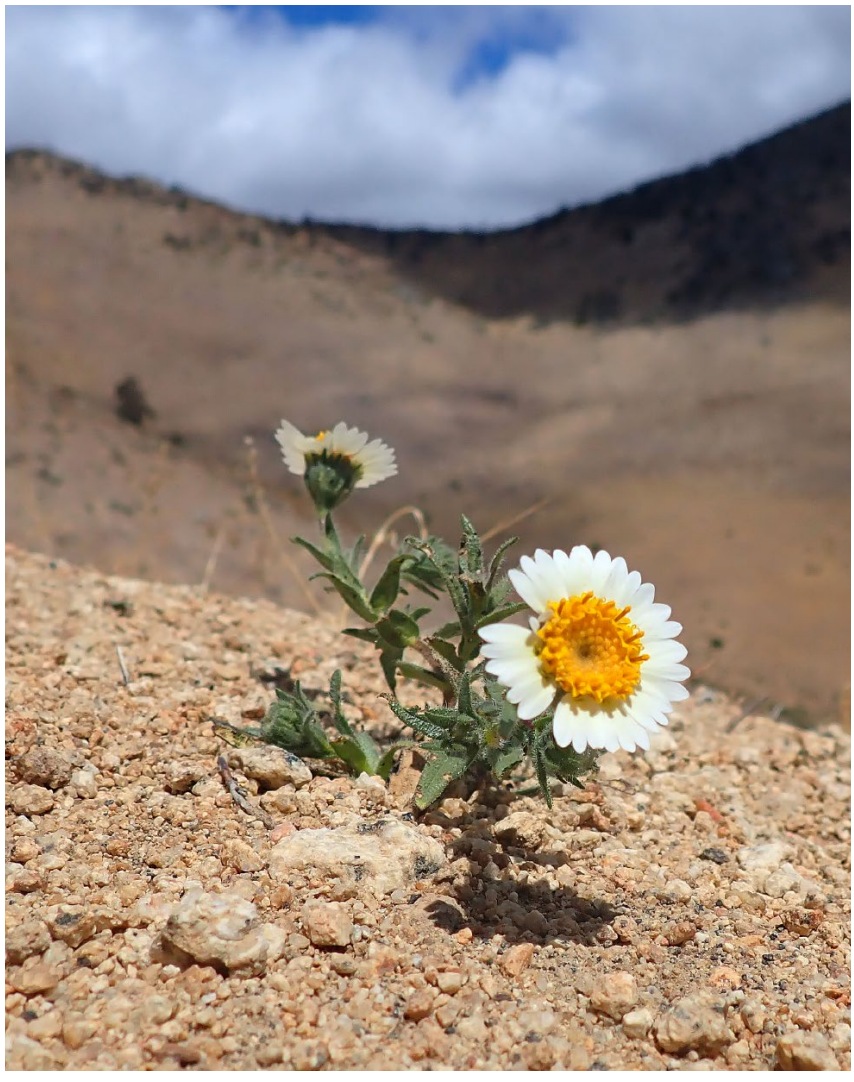

Figure 2. The jewel of California compositae Layia glandulosa Hook. \& Arn. grows in gravelly or sandy soils where it is an abundant part of ephemeral spring wildflower blooms. The spicy-scented glandular foliage, often dark purple tinted stems, heterogamous heads, and linear, long tapering awl-shaped disk pappus with woolly tufted bases set this species apart from other annual members of the Madieae Jeps. The ray florets can be white, yellow, cream, or lilac-tinged (or lacking in the derivative species L. discoidea D.D. Keck)

public, both to minimize potential damage from past fires and to prevent new ones from starting. Field work was looking like a harder prospect than we expected.

The fire season in California usually winds down in November with the arrival of rain, but in the winter of 2020/202 I a La Niña pattern had settled in the Pacific Ocean, and rain just never arrived. A few storms made it our way later in the winter, delivering solid precipitation to coastal sites, but by March, it was clear that we had to contend with one of the driest spring seasons that most botanists in California had witnessed in their lifetimes. Indeed, data from tree rings showed it to be among the six driest years in 500 years. At this point, we began to seriously doubt whether finding 100 populations of Layia glandulosa would even be possible, but we had to try!
In a dry year, the search for flowers becomes a much more complicated, slow-paced, and even interesting affair. We learned to recognize topographical microenvironments on the landscape that could have trapped more moisture, dips in the landscape where a decent bloom might be hiding. In the end, luck, rather than strategy was what saved us. One of our collaborators, Dr. Ryan O'Dell, had been paying special attention to L. glandulosa over the past ten years and had collected seeds of over 25 spatially distinct populations. Bruce began germinating these in a greenhouse in Berkeley, thinking they may be our only hope, and had success! By any measure, at least we wouldn't totally strike out. We headed to the field in April with low expectations, scouring dry creek beds and the bases of boulders for places where L. glandulosa may have germinated.

It was hard, hot, and uncomfortable field work, but there were redeeming moments as well. In the Peninsular Ranges of southern California, where only paltry Layia glandulosa could be found, some uncommon desert rarities were doing surprisingly well. These included flowering beavertail cacti

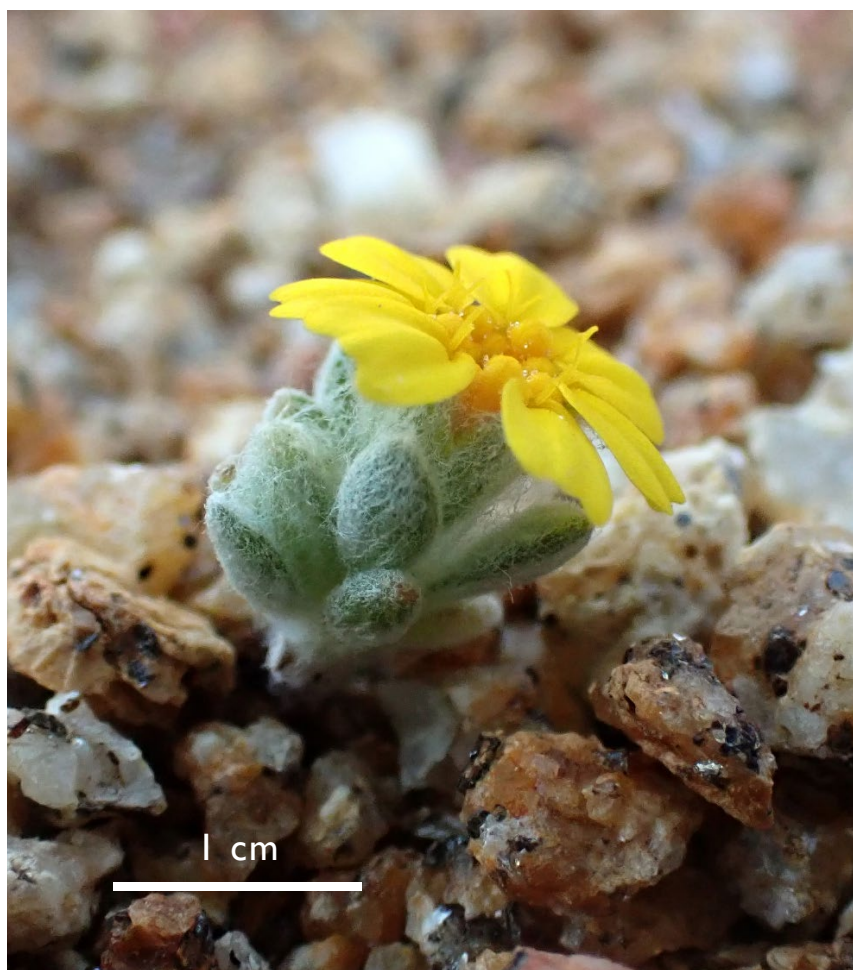

Figure 3. The often tufted, diminuitive annual Wallace's woolly daisy (Eriophyllum wallacei A. Gray) grows ephemerally in decomposed substrates and can be one of the few plants to bloom in a dry year. 
(Opuntia basilaris Engelm. \& J.M.Bigelow; Cactaceae), carpets of monkeyflowers (Diplacus bigelovii (A. Gray) G.L.Nesom; Phrymaceae), and the tiny threadplant (Nemacladus rubescens Greene; Campanulaceae), which harbors crystal structures within its diminutive flower that are presumably useful for attracting pollinators (Figure 5). Some interesting and very drought-resistant Compositae were in bloom, too, including members of the tribes Cichorieae (Calycoseris parryi A. Gray; Figure 6) and other tarweeds (Lagophylla ramosissima Nutt.; Figure 7), and the tiny Eriophyllum wallacei A. Gray (Figure 3). Shrubby comps in the genus Ericameria Nutt. were having an OK year, with Ericameria linearifolia (DC.) Urbatsch \& Wussow lighting up the hillsides. Coastal parts of southern California had fared better than other parts of the range of L. glandulosa in terms of total rain, and we had good luck in collecting plants from the rocky hillsides of the Coast and Transverse ranges. There, L. glandulosa shows its greatest amount of variability in flower color, including individuals with yellow, white, cream, or even pink to deep rose ray corollas. These trips were not without mishaps of their own, though, including runins with disgruntled property owners, belligerent authorities, and smelly hitchhiking Pacific Crest Trail hikers. Two large rattlesnakes made appearances on our field trips, startling us but inflicting no harm. On one trip, the back of a pickup truck was left open by mistake and all of the plant presses and camping gear ended up spread across the highway! Thanks to a quick search party response and some local desert dwelling do-gooders, everything was recovered intact. We were surprised by our success

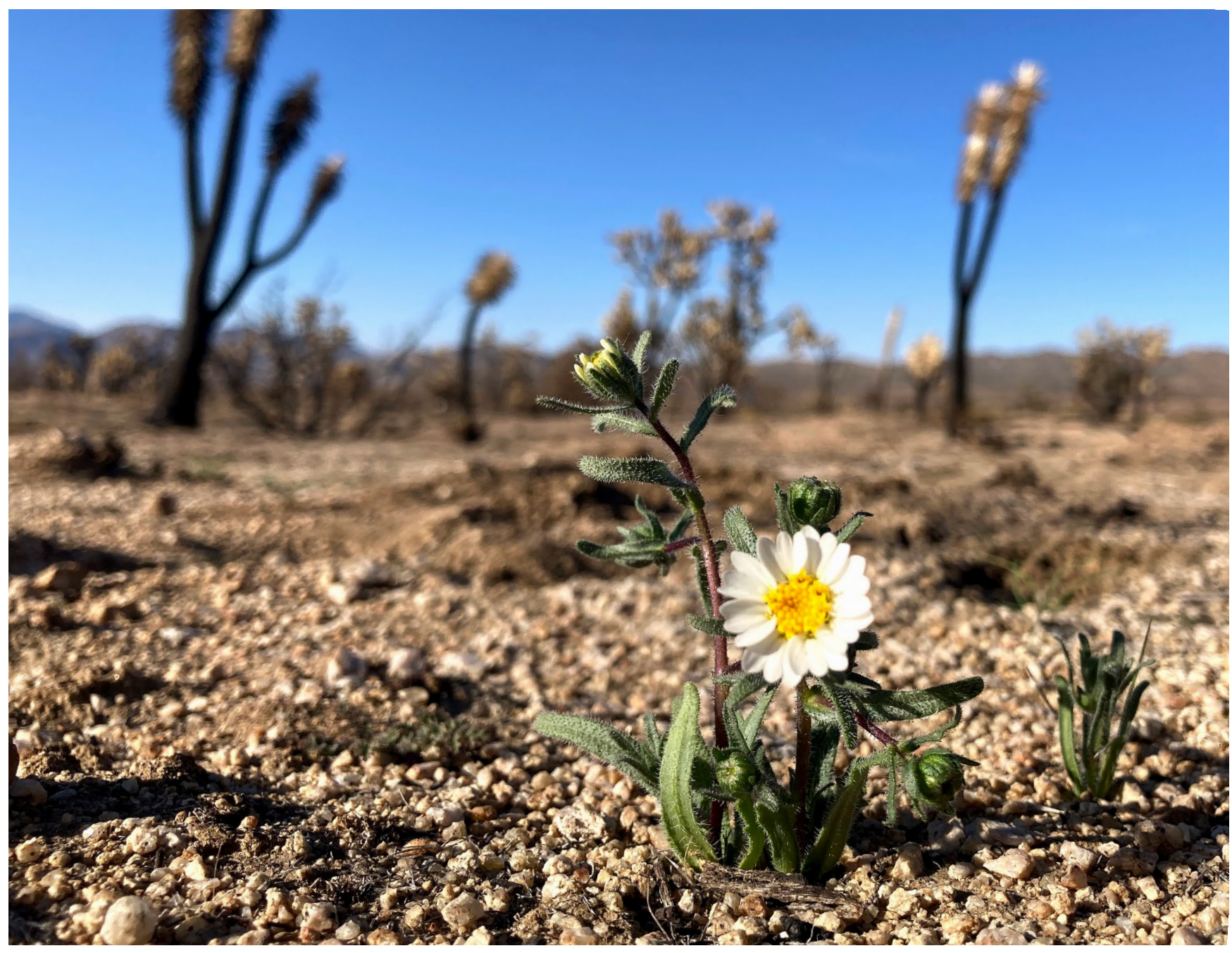

Figure 4. Dome fire in Mojave National Preserve was a catastrophe, burning over a million Joshua Trees (Yucca schidigera Ortgies, Asparagaceae) in a site deemed refuge for these plants under increasing climate change. In the scar of the burn during a spring without rain, we were surprised to find dense blooms of annual plants, including Layia glandulosa Hook. \& Arn. , among the charred remains of the woodland. 

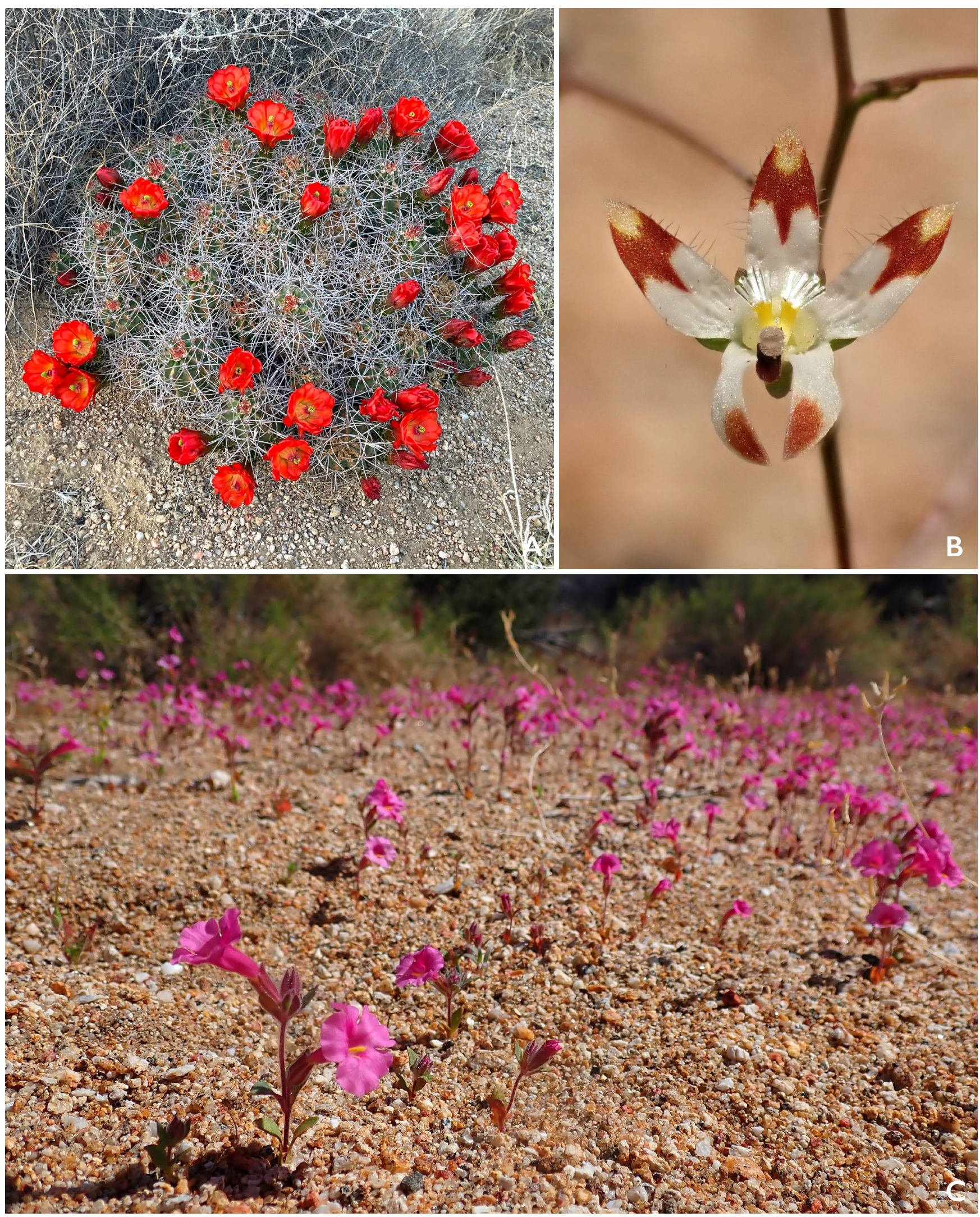

Figure 5. Desert rarities other than comps. A. Mojave Kingcup cactus (Echinocereus triglochidiatus ssp. mojavensis). B. Nemacladus rubescens Greene (Campanulaceae) is a tiny desert wildflower that contains shiny crystal-like structures that presumably serve to attract curious pollinators to these otherwise invisible little plants.. C. Bigelow's monkeyflower (Diplacus bieglovii (A.Gray) G.L.Nesom; (Phrymaceae). 

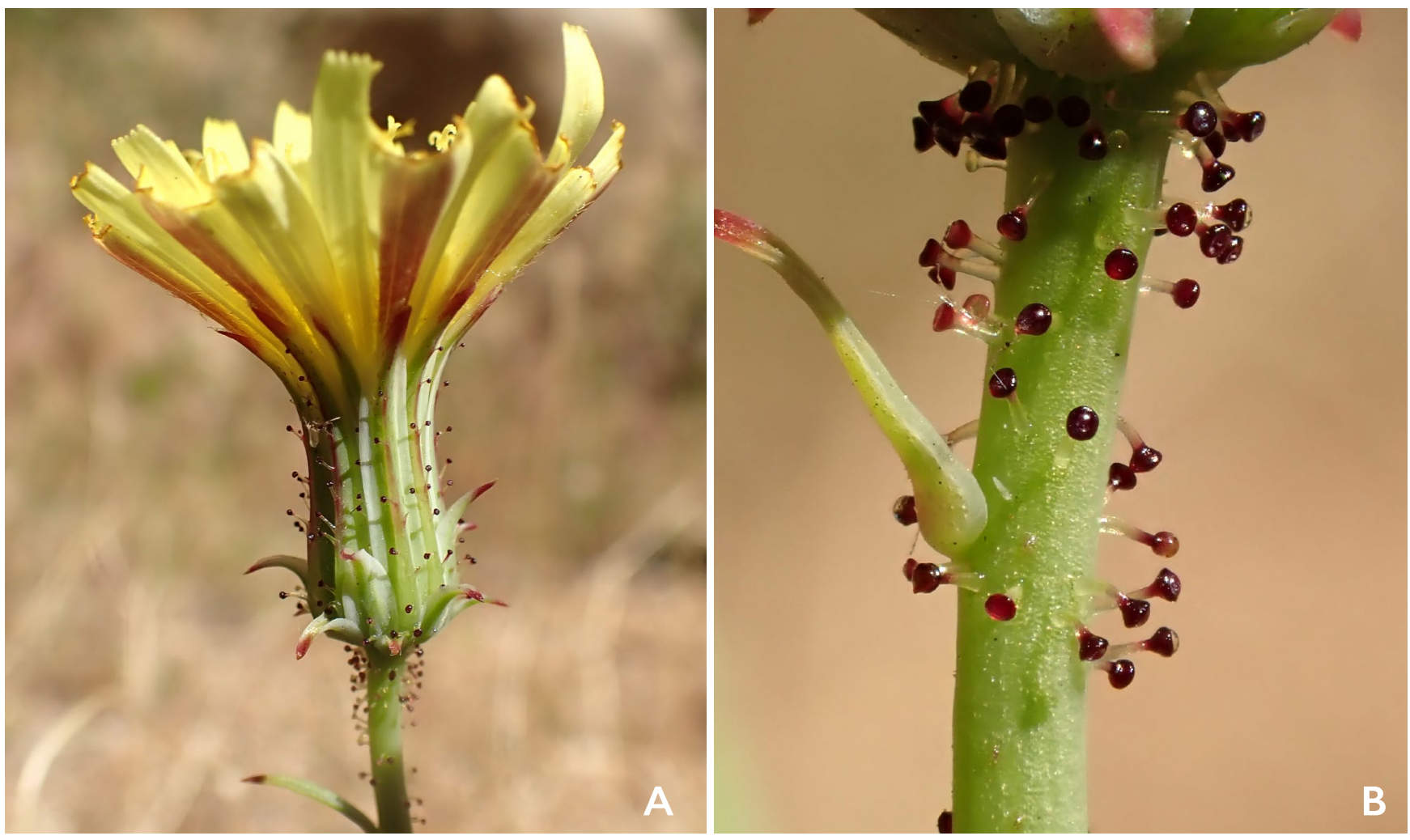

Figure 6. Yellow tack-stem (Calycoseris parryi A. Gray; Cichorieae) grows in low gravelly areas. A. Lateral view of the head. B. Close up of the conspicuously dotted stem with tack-shaped glandular trichomes.

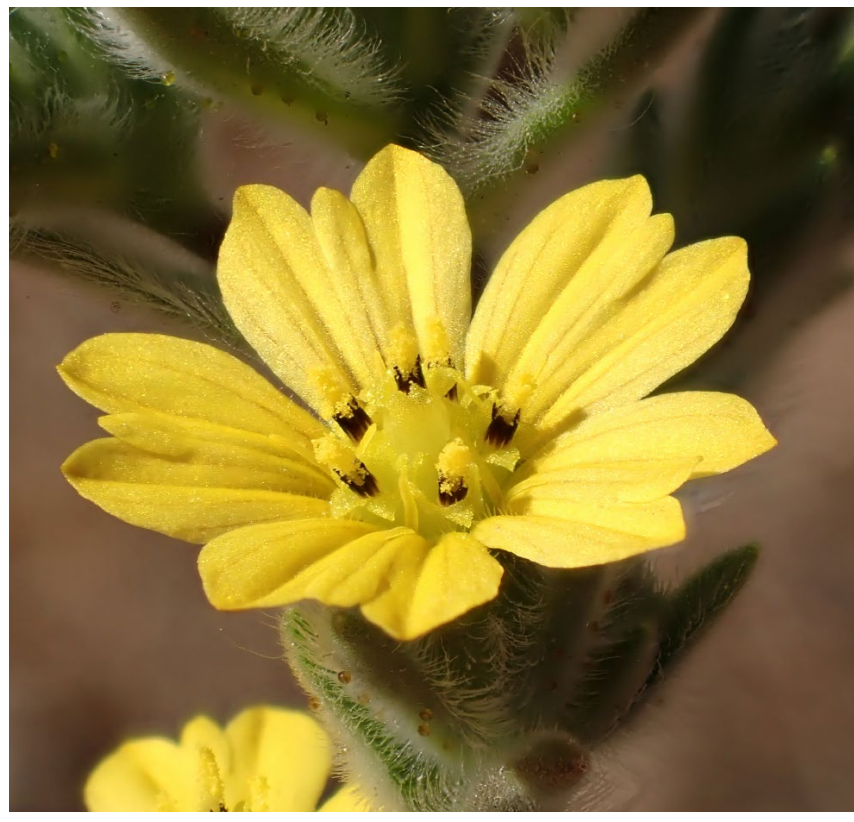

Figure 7. The hare-leaf (Lagophylla ramosissima Nutt.) is a selfcompatible annual tarweed (Madieae) with soft-hairy leaves, fan shaped rays, and yellow to golden brown glands that are attractive to look at but occasionally cause dermatitis on contact. early on in finding plants, by May we (Figure 9) had found about 70 populations of L. glandulosa despite the unprecedented drought, but the most difficult part of the species range lay ahead, the Mojave Desert.

The Mojave Desert is the highest and driest of the North American deserts and in many years, precipitation can be negligible or none. In a typical dry year one can still find blooms by looking in the creek beds and low spots, but this year even that strategy would not cut it. On our first visit to the Mojave we checked the low arroyos and found nothing. We checked the bases of boulders and cliffs where the water runs down - nothing. We even checked the ditches along roadsides - still nothing! Finally, in an act of desperation, we visited a popular hiking spot where plants had been posted many times on iNaturalist. The location was along a popular trail on Cima Dome in Mojave National Preserve, but upon arrival we found the entire area had recently been burned to a crisp by a fast moving wildfire known as the Dome Fire. We thought we 


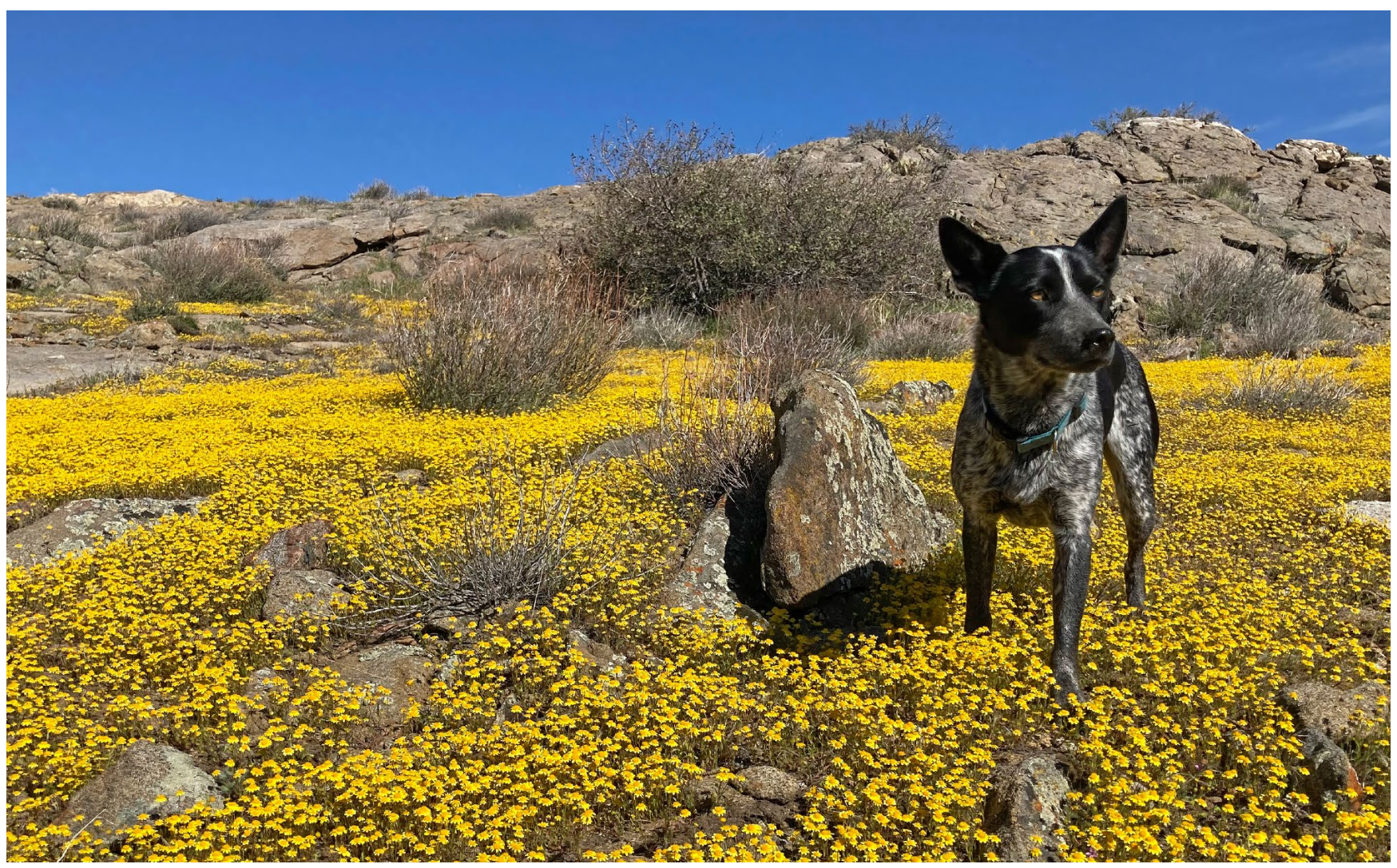

Figure 8. A key member of the collecting team, Rio, helped sniff out rare blooms in a drought year, such as this carpet of goldfields (Lasthenia gracilis (DC.) Greene) in the peninsular mountain ranges.

were out of luck, but when we walked the trail, to our surprise, there were flowers everywhere! Apparently, the heat and release of nutrients from the wildfire had stimulated a good wildflower bloom despite the complete lack of water (Figure 4). This was unheard of, since the convergence of drought and wildfire in the desert was such an exceedingly rare occurrence. It was even hard for us to believe. In the middle of a dry, drought-stricken desert with no germination for hundreds of miles we had found an abundance of wildflowers in the charred, blackened scar of a Joshua tree woodland! We found maps of the recent wildfires and burn scars turned out to be productive places to find L. glandulosa in other parts of the state, as well, helping us to finally fill out the remainder of gaps in our sampling up to 100 populations.

The global changes occurring now are unprecedented in scale and effect, and we don't have the slightest idea what future conditions will prove conducive for the growth of our plants. Being forced to search for plants in one of the hottest, driest, and most burnt years anybody could remember was challenging, but it also surprised us. The most unexpected discovery we made was that at the convergence of these multiple disasters, when all hope for finding plants seemed to be lost, in the most unlikely places, wildflowers will still grow.

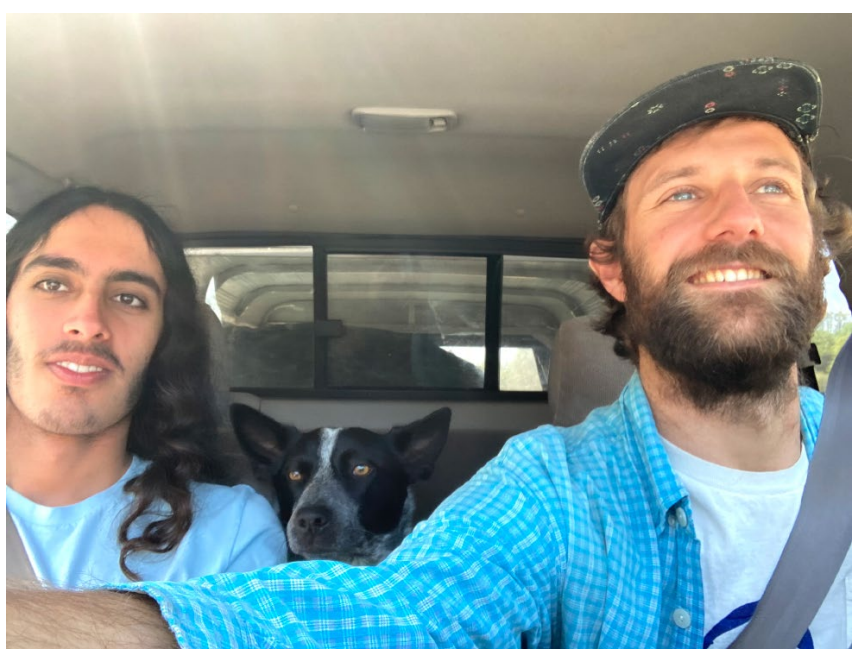

Figure 9. Part of the collecting team, from left to right: Armin Adley, Rio and Isaac Lichter-Mark. 


\section{ACKNOWLEDGEMENTS}

The whole genome phylogeography of Layia glandulosa project is supported by the California Conservation Genomics Project and our research team was made up of Armin Adley, Susan Fawcett, Ryan O'Dell, Bridget Wessa, and Sophia Winitsky. Thank you to J. Mauricio Bonifacino and the TICA newsletter committee for useful comments on our report from the field and The International Compositae Alliance for lots of inspiration along the way! 